\title{
Radiation-induced modification of polyurethane with hydroxyethyl methacrylate: blood compatibility
}

\author{
CHANDRA P SHARMA \\ Division of Biosurface Technology, Sree Chitra Tirunal Institute for Medical Sciences and \\ Technology, Poojapura, Trivandrum 695012, India \\ MS received 24 December 1982; revised 13 October 1984

\begin{abstract}
An attempt is made to develop the hydrophilic grafting of polyether urethane urea with hydroxyethyl methacrylate (HEMA) using ${ }^{60} \mathrm{Co} \gamma$-irradiation for achieving optimum hydrophilic/hydrophobic property needed towards blood compatibility. Contact angle method and platelet adhesion from calf's blood are used to determine the suitability of these
\end{abstract} \\ modified surfaces.
}

Keywords. Blood compatibility; platelet-adhesion; HEMA grafted polyether urethane; $\gamma$-irradiation.

\section{Introduction}

Surface energy and interfacial parameters of synthetic polymers have been of interest, since such parameters seem to have some inter-relationship (Lyman et al 1965) with blood compatibility. It has also been suggested (Sharma 1981a) that optimum distribution of polar-dispersion components on the surface may have sufficient bioadhesive potential to form a passivating layer, such that a more inert surface is presented to the blood. The good blood compatible surface can be achieved if surface energy parameters,

and

$$
\begin{aligned}
& \alpha_{s}\left(=\left(\gamma_{s}^{d}\right)^{1 / 2}\right) \simeq 4.7(\text { dynes } / \mathrm{cm})^{1 / 2}, \\
& \beta_{s}\left(=\left(\gamma_{s}^{p}\right)^{1 / 2}\right) \simeq 3.0(\text { dynes } / \mathrm{cm})^{1 / 2}
\end{aligned}
$$

$$
\beta_{s} / \alpha_{s} \quad \simeq 0.64 \text { are adjusted (Sharma 1981b). }
$$

We have therefore attempted to develop an optimum procedure to modify our polyurethane ureas, synthesised in our laboratory with polypropylene glycol (mol. wt. 1025) as described by Shibatani et al (1977) and characterised (Sharma and Ashalata 1982), with hydroxyethyl methacrylate (HEMA) using ${ }^{60} \mathrm{Co} \gamma$-irradiation to achieve the desired surface properties. Our polymer peuu had an initial tensile strength of $\sim 100 \mathrm{~kg} / \mathrm{cm}^{2}$ and $\%$ elongation of $\sim 157 \%$ for a gauge length of $25.4 \mathrm{~mm}$ and cross head speed $20 \mathrm{~mm} / \mathrm{min}$, with pore size $\sim 50-100 \mu$ and number of pores on the surface $\sim 5000 \pm 1000 / \mathrm{cm}^{2}$ as viewed microscopically.

\section{Method}

Polyether urethane ureas (PEUU) are fabricated in the form of vascular grafts $(5 \mathrm{~mm}$ diameter) from $30 \mathrm{~g} \%$ solution in dimethyl formamide as described earlier (Sharma and Ashalata 1982). 
These grafts are treated with acetone for $1-1 \frac{1}{2} \mathrm{hr}$ and kept in distilled water for $24 \mathrm{hr}$, changing the water several times. The samples are dried under vacuum at $343^{\circ} \mathrm{K}$ and weighed. Before swelling the samples, the HEMA (BDH, England) was evacuated and $\mathrm{N}_{2}$ gas continuously bubbled through it. Samples are dipped in HEMA for $\sim 5 \mathrm{~min}$ only since we want only the surface modification without much penetration of HEMA into the bulk of our samples. The samples are slightly pressed between two filter papers with constant pressure, and irradiation is performed on these samples at room temperature in a ${ }^{60} \mathrm{Co}$ gamma chamber with a constant dose rate of $0.25 \mathrm{M} \mathrm{rad} / \mathrm{hr}$ and strength of 843 Rongton $/ \mathrm{hr} / \mathrm{m}$ for different lengths of time up to $4 \mathrm{hr}$. After irradiation, the samples are treated with distilled ethanol for $48 \mathrm{hr}$ to remove all ungrafted HEMA monomer from the samples (Jansen and Ellinghorst 1979).

\section{Platelet adhesion}

Washed calf platelets are prepared and suspended in tyrode solution (Sharma and Lissy 1982) for adhesion studies. The polymers under study are exposed to platelet suspension for $1 \mathrm{hr}$, rinsed with buffer under uniform flow for about $3 \mathrm{~min}$, and the platelets are fixed with $2.5 \%$ glutaraldehyde and stained with Coomassie blue $\mathrm{G}$. The platelet density is detected using an optical microscope. Different fields are randomly read and averaged in a similar fashion for all samples.

\section{Evaluation of surface energy parameters}

The polymer surfaces are characterised using contact angle measurement (Zisman 1964) with a Goniometer at room temperature. The polymer films are cleaned by rinsing with ethanol. The organic liquids used for the measurements are more than $99 \%$ pure. The dispersion $\alpha_{s}\left(=\left(\gamma_{s}^{d}\right)^{1 / 2}\right)$ and polar $\beta_{s}\left(=\left(\gamma_{s}^{p}\right)^{1 / 2}\right)$ components of surface energy $\gamma_{s}$ are determined as described earlier (Sharma 1981b).

\section{Results and discussion}

The grafting yield and water uptake \% is determined gravimetrically (Jansen and Ellinghorst 1979). There is no significant grafting yield up to $2 \mathrm{hr}$ irradiation doses. Water uptake is also only $\sim 3 \%$. However $\sim 20 \%$ grafting yield is observed, when irradiation dose is $4 \mathrm{hr}$ and water uptake $\%$ increase up to $\sim 7 \%$. Inherent viscosity $\eta_{\text {inh }}$ (dimethyl formamide as a solvent at $\sim 30^{\circ} \mathrm{C}$ ) also increases gradually from $\sim 0.33$ $(d l / g)$ non-irradiated, to $\sim 0.61(\mathrm{dl} / \mathrm{g})$ after $4 \mathrm{hr}$ of irradiation indicating the possibility of crosslinking via grafting with irradiation doses.

No significant variation is observed (i.e. within standard deviation range) in the number of platelets adhered ( $\sim 3.5 \pm 0.7$ in all cases). Surface energy parameters seems to be affected with grafting. For $4 \mathrm{hr}$ irradiation dose, $\alpha_{s} \simeq 4.6(\text { dynes } / \mathrm{cm})^{1 / 2}$ and $\beta_{\mathrm{s}}$ $\simeq 3.8(\text { dynes } / \mathrm{cm})^{1 / 2}$ compared to $\alpha_{s} \simeq 4.9$ and $\beta_{s} \simeq 2.85\left(2 \mathrm{hr}\right.$, and $\alpha_{s} \simeq 5.1$ and $\beta_{s} \simeq 3.3$ (Bare i.e. non-irradiated).

Approximately $3 \mathrm{hr}$ of irradiation time is required to achieve surface energy parameters $\alpha_{s} \simeq 4.7(\text { dynes } / \mathrm{cm})^{1 / 2}$ and $\beta_{s} \simeq 3(\text { dynes } / \mathrm{cm})^{1 / 2}$ as suggested earlier (Sharma 1981b) for blood compatibility. Since such surfaces may absorb albumin 
preferentially (Lissy and Sharma 1981), adhesion of platelets will also be less in in vivo conditions instead of increasing due to hydrophilicity (Neumann et al 1979). Further increased dose may also lead to physical entanglement and crossilinking of homopolymerising HEMA in the PEUU metrics which may be difficult to extract afterwards (Jansen and Ellinghorst 1979).

Our future efforts will be to study in depth and extend the above studies and also develope biological interrelation with such concepts as described elsewhere (Nair and Sharma 1984) considering interaction with platelets and plasma proteins on such surfaces.

\section{Acknowledgements}

The author appreciates the help received from Dr V N Krishnamurthy for ${ }^{60} \mathrm{Co}$ irradiation of the samples, Dr A V Lal for providing calf blood, and Miss M K Sheela, Mr Thomas Chandy and Miss Geetha Kurian for suggestion and assistance. This work has been supported by DST.

\section{References}

Jansen B and Ellinghorst G J 1979 J. Polym. Sci., Polym. Symp. 66465

Lyman D J, Muir W M and Lee I J 1965 Trans. Am. Soc. Artif. Intern. Organs 21302

Nair A and Sharma C P 1984 Curr. Sci. (in press)

Neumann A W, Moscarello M A, Zingg W, Hum O S and Chang S K 1979 J. Polym. Sci., Polym. Symp. 66391

Paul Lissy and Sharma C P 1981 J. Colloid Interface Sci. 84546

Sharma C P 1981a J. Biomechanics 14813

Sharma C P1981b Biomaterials 257

Sharma C. P and Ashalatha P V 1982 Cell. Polym. (in press)

Sharma C P and Lissy P 1982 J. Colloid Interface Sci. 87436

Shibatani K, Lyman D J, Shich D F and Knutson K 1977 J. Polym. Sci., Polym. Chem. Edu. 151655

Zisman W A 1964 Relations of the equilibrium contact angle to liquid and solid constitution, chapter 1, Adv. Chem. Ser. 43, Am. Chem. Soc., Washington DC 19 